October 29, 2018

\title{
Measurement of Ultra-Low Potassium Contaminations with Accelerator Mass Spectrometry
}

\author{
K.J. Dong ${ }^{a, b}$, H.T. Wong ${ }^{b, *}$, M. He $^{a}$, S. Jiang ${ }^{a}$, \\ J.Z. Qiu ${ }^{a, c}$, Y.J. Guan ${ }^{a, d}$, S.Y. Wu ${ }^{a}$, J. Yuan ${ }^{a}$ \\ ${ }^{a}$ Department of Nuclear Physics, China Institute of Atomic Energy, Beijing 102413. \\ ${ }^{b}$ Institute of Physics, Academia Sinica, Taipei 11529. \\ ${ }^{c}$ Armed Police Force Academy, Langfang 065000. \\ ${ }^{d}$ Department of Physics, Guanxi University, Nanning 530004.
}

\begin{abstract}
Levels of trace radiopurity in active detector materials is a subject of major concern in low-background experiments. Among the radio-isotopes, ${ }^{40} \mathrm{~K}$ is one of the most abundant and yet whose signatures are difficult to reject. Procedures were devised to measure trace potassium concentrations in the inorganic salt CsI as well as in organic liquid scintillator (LS) with Accelerator Mass Spectrometry (AMS), giving, respectively, the ${ }^{40} \mathrm{~K}$-contamination levels of $\sim 10^{-10}$ and $\sim 10^{-13} \mathrm{~g} / \mathrm{g}$. Measurement flexibilities and sensitivities are improved over conventional methods. The projected limiting sensitivities if no excess of potassium signals had been observed over background are $8 \times 10^{-13} \mathrm{~g} / \mathrm{g}$ and $3 \times 10^{-17} \mathrm{~g} / \mathrm{g}$ for the CsI and LS, respectively. Studies of the LS samples indicate that the radioactive contaminations come mainly in the dye solutes, while the base solvents are orders of magnitude cleaner. The work demonstrate the possibilities of measuring naturally-occurring isotopes with the AMS techniques.
\end{abstract}

PACS Codes: 07.75.+h, 92.20.Td, 41.75.-i

Keywords: Mass spectrometers, Radioactivity, Charged-particle beams

${ }^{*}$ Corresponding author: Email: htwong@phys.sinica.edu.tw; Tel:+886-2-2789-6789; FAX:+886-2-27889828. 


\section{Introduction}

Accelerator Mass Spectrometry (AMS) [3] is an established technique for the detection and measurement of trace level of long-lived radionuclides [4] such as ${ }^{14} \mathrm{C},{ }^{10} \mathrm{Be},{ }^{36} \mathrm{Cl}$. It improves over conventional techniques such as neutron activation analysis (NAA), inductively-coupled plasma mass spectrometry (ICP-MS) as well as secondary ion mass spectrometry (SIMS), and has been successfully applied to a wide variety of disciplines like archeology, geology, environmental science, biomedicine, safeguards of nuclear materials and so on [5].

Measurement of trace concentrations of naturally-occurring, as well as cosmic-ray or fission induced radioactive isotopes is an important technique with major impact to low background experiments [1]. The TEXONO Collaboration is pursuing a research program in low energy neutrino and astroparticle physics [2]. An important aspect is to devise procedures for measuring such trace radiopurity using the AMS techniques. Significant improvements in sensitivities and flexibilities over existing methods can be expected. Results were published already for the measurement of trace ${ }^{129} \mathrm{I}$ [6] in inorganic crystal and organic liquid scintillator (LS). The isotope ${ }^{129} \mathrm{I}$ is a long-lived fission fragment, where the corresponding AMS procedures are already matured and well-established. In this article. we report on our efforts and results on potassium $\left({ }^{39} \mathrm{~K}\right)$. The isotope ${ }^{39} \mathrm{~K}$ is stable and exists in large abundance in nature - and there are no prior attempts to measure trace abundance of it with AMS. These poses new experimental challenges and the results reported here represent advances in the field.

Potassium has three naturally-occurring isotopes: ${ }^{39} \mathrm{~K},{ }^{40} \mathrm{~K}$ and ${ }^{41} \mathrm{~K}$ with isotopic abundances of $93.26 \%, 0.0117 \%$ and $6.73 \%$, respectively. Among these, ${ }^{39} \mathrm{~K}$ and ${ }^{41} \mathrm{~K}$ are stable while ${ }^{40} \mathrm{~K}$ has a half-live of $1.248 \times 10^{9}$ years, where the dominant decay channels are:

$$
{ }^{40} \mathrm{~K} \rightarrow{ }^{40} \mathrm{Ca}+\mathrm{e}^{-}+\overline{\nu_{\mathrm{e}}} \quad\left(\mathrm{BR}=89 \% ; \mathrm{Q}_{\beta^{-}}=1.31 \mathrm{MeV}\right)
$$

and

$$
\begin{aligned}
& { }^{40} \mathrm{~K}+\mathrm{e}^{-} \rightarrow{ }^{40} \mathrm{Ar}^{*}+\nu_{\mathrm{e}} \quad\left(\mathrm{BR}=11 \% ; \mathrm{Q}_{\mathrm{EC}}=1.51 \mathrm{MeV}\right) \\
& { }^{40} \mathrm{Ar}^{*} \quad \rightarrow \quad{ }^{40} \mathrm{Ar}+\gamma \quad\left(\mathrm{E}_{\gamma}=1.461 \mathrm{MeV}\right) \text {. }
\end{aligned}
$$

Both decays pose severe background problems to low-count-rate experiments where the signals are at the sub-MeV energy range, such as the studies of pp and ${ }^{7}$ Be solar neutrinos, the searches of Cold Dark Matter, as well as of neutrino magnetic moments with reactor neutrinos [1]. Potassium contaminations in the active detector materials will give rise to a continuous $\beta$-decay background up to $1.31 \mathrm{MeV}$, while those in the passive materials 


\begin{tabular}{|l|ccccc|}
\hline $\begin{array}{l}\text { Techniques } \\
\text { Reference }\end{array}$ & $\begin{array}{c}\text { HPGe } \\
{[8]}\end{array}$ & $\begin{array}{c}\text { CTF } \\
{[9]}\end{array}$ & {$[10]$} & {$[11]$} & This Work \\
\hline \hline Sample Size & $\sim 1 \mathrm{~kg}$ & 4 ton & $202 \mathrm{~g}$ & $353 \mathrm{~g}$ & $86.5 \mathrm{~g}$ \\
Sample Type & No & Only LS & No & No & No \\
\hline${ }^{40} \mathrm{~K} /$ sample $](\mathrm{g} / \mathrm{g})$ & $<10^{-10 *}$ & $<10^{-15 \dagger}$ & $<4 \times 10^{-16 \dagger}$ & $<2 \times 10^{-15 \dagger}$ & $\sim 10^{-13}(\mathrm{LS})^{\ddagger}$ \\
& & & & & $\sim 10^{-15}(\mathrm{PC})^{\ddagger}$ \\
& & & & & $<3 \times 10^{-17} \mathrm{U}$ \\
\hline
\end{tabular}

* Typical sensitivities for a variety of samples

$\dagger$ Custom-prepared ultra-pure liquid scintillator samples

$\ddagger$ Commercially produced liquid scintillator (LS) and pseudocumene (PC) samples

${ }^{\amalg}$ Projected limit if no ${ }^{39} \mathrm{~K}$ signals are observed

Table 1: Comparisons of the various techniques for ultra-low potassium measurements.

in the vicinity of the detector will produce $\gamma$-rays at $1.46 \mathrm{MeV}$ which, after Compton scatterings, can lead to background at the sub-MeV range. The suppression and an efficient measurement technique of ultra-low amount of potassium in a wide spectrum of materials are therefore an issue of crucial significance. As an illustrative example, in order for the BOREXINO and KamLAND experiments to achieve the goals of studying the low energy ${ }^{7} \mathrm{Be}$ solar neutrinos with LS, the required contaminations of ${ }^{40} \mathrm{~K}$ should be less than $10^{-18} \mathrm{~g} / \mathrm{g}$.

While the radioactive isotope of interest to low background experiments is ${ }^{40} \mathrm{~K}$, the AMS techniques devised in this work are for the measurement of ${ }^{39} \mathrm{~K}$. The ${ }^{39} \mathrm{~K}$-to- ${ }^{40} \mathrm{~K}$ ratio of 7971:1 is constant for naturally-occurring materials. Therefore, a measurement of ultra-low ${ }^{40} \mathrm{~K}$ radio-purities is equivalent to one on the level of ${ }^{39} \mathrm{~K}$-contaminations, but with a sensitivity enhancement factor of almost $10^{4}$. In addition, ${ }^{40} \mathrm{~K}$ measurements by the AMS techniques are vulnerable to background contaminations by ${ }^{40} \mathrm{Ca}$, a stable isotope which exists in abundance in nature.

The sensitivities of the various techniques to the measurement of ultra-low ${ }^{40} \mathrm{~K}$ contaminations are shown in Table 1. Photon counting of the $1.461 \mathrm{MeV} \gamma$-line by high-purity germanium detectors (HPGe) [8] is limited by the ambient background. The Counting Test Facility (CTF) [9] at the Gran Sasso Laboratory is a 4 ton LS detector. It took $\sim 30$ days to measure only a single sample of LS, and is therefore of limited flexibilities. To address these drawbacks, the NAA techniques for potassium $[10,11]$ were recently developed, where the sensitivities of $10^{-15}-10^{-16} \mathrm{~g} / \mathrm{g}$ were achieved. In this paper, we present results on a complementary approach using the AMS techniques. 
The AMS techniques were adopted to tackle this problem because of its promises on sensitivities and versatilities. An organic liquid and an inorganic salt were selected for studies. Once the procedures are established, different batches of samples, each requiring little mass, can be measured in relatively short time. The techniques developed can be easily adapted to other isotopes in trace concentrations, and with different carrier materials.

In a broader context, the studies represent also the direction of extending the frontiers of the AMS techniques to include stable and naturally-occurring isotopes, complementary to the research efforts by other groups working on precious metals in minerals [12] as well as various impurities in semiconductors [15]. The AMS detection limits for stable isotopes are in general of the range of $10^{-12}$, due to the difficulties of establishing an ultra-clean condition in an accelerator environment. The techniques of background suppression are being intensely pursued by the communities working on low-background experiments. Future advances in these domains may also lead to improvement in the AMS sensitivities on the naturally-occurring isotopes.

\section{Experimental Set-Up and Procedures}

The investigations reported in this article were conducted at at the $13 \mathrm{MV}$ Tandem Accelerator Facility China Institute of Atomic Energy (CIAE) [16]. The optimized configuration for AMS applications is shown schematically in Figure 1.

An organic liquid and an inorganic salt were selected as the sampling materials since they require different experimental procedures and systematic effect considerations. The organic liquid studied is the standard liquid scintillator (LS) mixture - the dye PPO [2,5diphenyloxazole] in powder form dissolving in the organic solvent pseudocumene (PC) $[1,3,5 \text {-trimethylbenzene }]^{\dagger}$. The inorganic salt selected was CsI powder ${ }^{\ddagger}$, since $\mathrm{CsI}(\mathrm{Tl})$ crystal scintillators are being used in reactor neutrino [13] and dark matter [14] experiments. The processing and measurement procedures are expected to be similar with other organic solvent and dyes or inorganic salts.

\section{$2.1 \quad$ Pre-processing}

No chemical procedures are necessary for the CsI powder which was directly used in the AMS measurement. However, CsI is a hygroscopic material which can easily lead to

\footnotetext{
†Supplier: Gaonengkedi Science \& Technology Co. Ltd., China

${ }^{\ddagger}$ Supplier: Chemtall GMBH, Germany
} 
injector magnet excursion. Accordingly, the CsI samples were deposited quickly on to a cathode of electrolytic aluminium in a clean dry box. The cathode was then baked in an oven at $100^{\circ} \mathrm{C}$ for two days prior to the measurement.

The LS pre-processing procedures were adapted from those of Refs. [10]\&[11]. Different LS samples were prepared with different concentrations of PPO dissolved in pure PC. The procedures are summarized by the flow chart of Figure 2. All steps were carried out in clean rooms better than the Class-100 grade. Polypropylene bottles were etched in ultrapure nitric acid and ultra-pure hydrochloric acid over 5 days. The bottles were then rinsed with ultra-pure water and then pure PC, before left to be dried. The LS samples were stored into these bottles for further processing.

Quartz crucibles were etched with 65\% ultra-pure hydrochloric acid and $65 \%$ ultrapure nitric acid over a period of one week at sub-boiling temperature. Then they were rinsed with $65 \%$ ultra-pure nitric acid and dried at sub-boiling temperature. The LS samples were emptied to the crucibles and evaporated under a vacuum of about 20 Torr. The solid residual left behind was mostly PPO powder, the least volatile component. The mass of solid residuals after evaporation is typically less than $1 \%$ of the LS samples. Strong nitric acid was subsequently added to extract the trace elements from the residuals. The acid was heated to $80^{\circ} \mathrm{C}$ on a hot plate. At this temperature, the PPO samples fully dissolved into the acid, forming a transparent yellow solution where the potassium ions entered the acid phase. Ultra-pure copper ${ }^{\S}$ with specified potassium concentrations of less than $10 \mathrm{ppb}$ was dissolved into the acid solution. The $\mathrm{Cu}\left(\mathrm{NO}_{3}\right)_{2}$ solution was evaporated slowly at $100^{\circ} \mathrm{C}$. The residual solid was further baked at $200^{\circ} \mathrm{C}$ for two hours. The final substance was mostly $\mathrm{CuO}$, while the trace amounts of potassium existed as $\mathrm{KNO}_{3}$. These residual solid samples were used as target materials and measured by AMS directly. Only a few volatile potassium compounds exist, such that good recovery of the potassium contaminations from the original LS samples can be expected.

\subsection{Injector, Accelerator and Detector}

The ${ }^{39} \mathrm{~K}$ concentration in the CsI powder and in the LS were measured with CIAE-AMS facility depicted schematically in Figure 1. The tandem accelerator operated at a terminal voltage of 8.0 MV. A "Multi-Cathode Source of Negative Ions by Cesium Sputtering" was used as the negative ion source. Forty samples were positioned on the target wheel at one time. The wheel could be rotated without affecting the vacuum conditions such that stable operating configurations were maintained during measurements of a group of

\footnotetext{
${ }^{\S}$ Supplier: Alfa Aesar
} 
samples. For normalizations, the intensities of the ${ }^{127} \mathrm{I}^{-}$and ${ }^{63} \mathrm{Cu}^{-}$relative to ${ }^{39} \mathrm{~K}^{-}$ions extracted with cesium sputter source were measured by the Low Energy Faraday Cup (LECup).

The extracted ${ }^{39} \mathrm{~K}^{-}$ions were focused by a trim einzel lens and a double focusing $90^{\circ}$ deflecting magnet where the negative ion beams of interest were momentum selected. The ions were guided to an aperture of $2 \mathrm{~mm}$ diameter located at the entrance of the pre-acceleration tube, where they were accelerated up to about $120 \mathrm{keV}$ kinetic energy. The main accelerator operating at a terminal voltage of $7.4 \mathrm{MV}$ further boost the ions to to $67 \mathrm{MeV}$. A carbon foil was attached at the head of accelerator. The molecular background was eliminated due to break-up of molecular ions.

After passing through the accelerator tank, ions with charged state $8^{+}$were selected by a $90^{\circ}$ double focusing analyzing magnet with a mass energy product $\left(\mathrm{M} \cdot \mathrm{E} / \mathrm{Z}^{2}\right)$ at 200 to suppress the isotopic background. A high-resolution electrostatic deflector was placed at a branch beam line to further reduce the isotopic background and other undesired beam components. The ${ }^{39} \mathrm{~K}$-ions which survived all selections were detected by a goldsilicon surface barrier detector, The ${ }^{39} \mathrm{~K}$ count rates as a function of time were recorded for subsequent analysis.

\section{Measurements and Results}

Typical data taking of a certain sample consisted of 16 sequential measurements each lasting $100 \mathrm{~s}$, as depicted in Figure 3 for some selected samples. Steady state was reached after several hundred seconds. The quoted ${ }^{39} \mathrm{~K}$-levels were derived from the means of those ten measurements from $600 \mathrm{~s}$ to $1600 \mathrm{~s}$. Typical statistical errors of individual measurement is less than $1 \%$, while the variance of the ten measurements are of the order of $10 \%$. The variances include systematic effects like unstable hardware conditions during data taking, and are adopted as the measurement uncertainties.

\subsection{Blind Target}

In a typical AMS measurement, the samples are placed inside a $1 \mathrm{~mm}$ diameter hole drilled out of a target structure made of electrolytic aluminium. The negative ions are then focused on to this hole.

Measurements were performed with "blind" targets where the target structure was replaced by a piece of solid metal. This allowed measurements of the intrinsic background due to ambient contaminations and accelerator operation. Three target materials were 


\begin{tabular}{|l|c|cc|}
\hline Measuring Cup & $\begin{array}{c}\text { Beam Current } \\
\text { (nA) }\end{array}$ & \multicolumn{2}{|c|}{ Transmission Efficiency } \\
\hline \hline Low Energy Cup & 900 & 1.00 & 1.00 \\
Image Cup & 350 & 0.39 & 0.39 \\
AMS Cup & 150 & 0.43 & 0.17 \\
\hline
\end{tabular}

Table 2: Beam currents and transmission efficiencies of the negative ${ }^{37} \mathrm{Cl}$ ions.

selected: ultra-pure $(<\mathrm{ppm})$ copper, electrolytic copper and electrolytic aluminium. The variations of their ${ }^{39} \mathrm{~K}$ background at the AMS detector with time are displayed in Figure 4. The initial enhancement of background are due to surface contaminations of the target materials not relevant to subsequent studies, while the steady-state rates represents the upper bounds of the ion beam and accelerator background. The steady levels of the order of $10{ }^{39}$ K-events per second are at least factors of 100's less than the typical rates in the measurements of various samples $\left(>1000 \mathrm{~s}^{-1}\right)$, such that the accelerator-related background can be neglected.

\subsection{Inorganic CsI Powder}

The contaminations of ${ }^{39} \mathrm{~K}$ in CsI were directly measured by counting methods with the AMS detector, using KI as the reference sample. For optimizations of the accelerator parameters on ${ }^{39} \mathrm{~K}$ as well as the evaluations of the transmission efficiencies, a similar isotope ${ }^{37} \mathrm{Cl}$ was used. Negative ${ }^{37} \mathrm{Cl}$ ions from $\mathrm{AgCl}$ were emitted from the source and were accelerated by a terminal voltage of $8.2 \mathrm{MeV}$. Charge states of ${ }^{37} \mathrm{Cl}^{8+}$ were selected. The beam currents measured at the various stages are displayed in Table 2, from which the transmission efficiencies can be evaluated.

The two measurements on CsI and KI were normalized by the LECup currents on the common ${ }^{127} \mathrm{I}^{-}$ions, denoted by $\mathrm{I}_{\mathrm{LE}}\left({ }^{127} \mathrm{I}^{-}\right)$. The ${ }^{39} \mathrm{~K}$ contents in KI were measured as beam currents in the Image Cup, and compared to the ${ }^{39} \mathrm{~K}$-counts at the AMS detector in the CsI run, taking into account the transmission efficiency of $43 \%$ between the Image Cup and the AMS detector as shown in Table 2. The known relation of

$$
\mathrm{R}_{\mathrm{LE}}\left({ }^{127} \mathrm{I}^{-}\right)=6.25 \times 10^{9} \cdot\left[\mathrm{I}_{\mathrm{LE}}\left({ }^{127} \mathrm{I}^{-}\right) / \mathrm{nA}\right]
$$

was applied, where $\mathrm{R}_{\mathrm{LE}}\left({ }^{127} \mathrm{I}^{-}\right)$is the ${ }^{127} \mathrm{I}^{-}$-counts passing through the image cup per second. The measured contamination levels of potassium are:

$$
\begin{aligned}
& {\left[{ }^{39} \mathrm{~K} / \mathrm{CsI}\right]=(5.6 \pm 1.7) \times 10^{-7} \mathrm{~g} / \mathrm{g}, \text { or equivalently }} \\
& {\left[{ }^{40} \mathrm{~K} / \mathrm{CsI}\right]=(7.0 \pm 2.1) \times 10^{-11} \mathrm{~g} / \mathrm{g}}
\end{aligned}
$$


This implies an activity ${ }^{40} \mathrm{~K}$ decays in CsI of $1540 \pm 460 \mathrm{~kg}^{-1}$ day $^{-1}$. This result is consistent with and improves over that of an independent measurement on the CsI powder by direct counting of the $1461 \mathrm{keV}$ photons with a high-purity germanium detector, where only an upper limit

$$
\left[{ }^{40} \mathrm{~K} / \mathrm{CsI}\right]<2 \times 10^{-10} \mathrm{~g} / \mathrm{g}
$$

could be derived.

As an illustrative comparison, the intrinsic contaminations of ${ }^{137} \mathrm{Cs}$ and the $\mathrm{U}+\mathrm{Th}$ series in $\mathrm{CsI}(\mathrm{Tl})$ crystals were recently studied [17], where the levels of

$$
\begin{aligned}
{\left[{ }^{137} \mathrm{Cs} / \mathrm{CsI}(\mathrm{Tl})\right] } & =(1.7 \pm 0.3) \times 10^{-17} \mathrm{~g} / \mathrm{g}, \\
{\left[{ }^{232} \mathrm{Th} / \mathrm{CsI}(\mathrm{Tl})\right] } & =(2.23 \pm 0.06) \times 10^{-12} \mathrm{~g} / \mathrm{g}, \\
{\left[{ }^{238} \mathrm{U} / \mathrm{CsI}(\mathrm{Tl})\right] } & =(8.2 \pm 0.2) \times 10^{-13} \mathrm{~g} / \mathrm{g} \text { and } \\
{\left[{ }^{235} \mathrm{U} / \mathrm{CsI}(\mathrm{Tl})\right] } & <4.9 \times 10^{-13} \mathrm{~g} / \mathrm{g}
\end{aligned}
$$

were derived. These results confirm the expectations that the potassium contaminations in most materials are usually higher than those of the other isotopes which also exist in abundance in nature.

\subsection{Organic Solid and Liquid}

The results of the various runs with different organic samples are summarized in Table 3. As discussed in Section 2.1 and illustrated in Figure 2, the chemical pre-processing of the samples turned them into solid powder mixtures of $\mathrm{CuO}+\mathrm{KNO}_{3}$. Consequently, the AMS measurements of the ${ }^{39} \mathrm{~K}$ levels in the samples were all made relative to ${ }^{63} \mathrm{Cu}$. The time evolution of the 16 measurements for some selected samples are displayed in Figure 3 as illustrations. The raw data for each configuration include the mean and variance of the ${ }^{39} \mathrm{~K}$-counts in $100 \mathrm{~s}$, s well as the ${ }^{63} \mathrm{Cu}^{-}$beam currents at the LECup.

All the 13 measurements listed in Table 3 were performed within 12 hours where the accelerator operation has been stable. The calibration sample served to establish a relationship between ${ }^{39} \mathrm{~K}$-counts and ${ }^{63} \mathrm{Cu}^{-}$beam currents with the known $\left[{ }^{39} \mathrm{~K} / \mathrm{Cu}\right]$ contamination level. The good agreement of the cross-check samples with expected results, as well as the internal consistencies of the measured $\left[{ }^{39} \mathrm{~K} /\right.$ sample] levels among the different categories of samples, demonstrate that the experimental conditions were constant throughout the measurements, and that a single calibration relation can be applied consistently to all data.

The details of the measurements are elaborated in the following sub-sections. 


\begin{tabular}{|c|c|c|c|}
\hline Samples & $\begin{array}{c}{\left[{ }^{39} \mathrm{~K} / \mathrm{Cu}\right]} \\
(\mathrm{g} / \mathrm{g}) \\
\end{array}$ & $\begin{array}{c}{\left[{ }^{39} \mathrm{~K} / \text { Sample }\right]} \\
(\mathrm{g} / \mathrm{g}) \\
\end{array}$ & $\begin{array}{c}{\left[{ }^{40} \mathrm{~K} / \text { Sample }\right]} \\
(\mathrm{g} / \mathrm{g}) \\
\end{array}$ \\
\hline$\frac{\underline{\text { Blank }}}{\text { No Sample }}$ & $(1.6 \pm 0.1) \times 10^{-8}$ & - & - \\
\hline$\frac{\text { Calibration }}{\left[{ }^{39} \mathrm{~K} / \mathrm{Cu}\right]}=1.5 \mathrm{e}-7 \mathrm{~g} / \mathrm{g}$ & - & - & - \\
\hline $\begin{array}{l}\text { Cross-Checks } \\
{\left[{ }^{39} \mathrm{~K} / \mathrm{Cu}\right]=1.5 \mathrm{e}-8 \mathrm{~g} / \mathrm{g}} \\
{\left[{ }^{39} \mathrm{~K} / \mathrm{Cu}\right]=1.5 \mathrm{e}-9 \mathrm{~g} / \mathrm{g}}\end{array}$ & $\begin{array}{l}(1.7 \pm 0.2) \times 10^{-8} \\
(2.4 \pm 2.0) \times 10^{-9}\end{array}$ & - & - \\
\hline $\begin{array}{l}\text { PPO Powder } \\
\text { mass }=1.8 \mathrm{mg} \\
\text { mass }=19 \mathrm{mg} \\
\text { mass }=107 \mathrm{mg}\end{array}$ & $\begin{array}{l}(9.5 \pm 0.7) \times 10^{-8} \\
(9.8 \pm 1.0) \times 10^{-7} \\
(5.8 \pm 0.2) \times 10^{-6}\end{array}$ & $\begin{array}{l}(5.3 \pm 0.4) \times 10^{-7} \\
(5.2 \pm 0.5) \times 10^{-7} \\
(5.4 \pm 0.2) \times 10^{-7}\end{array}$ & $\begin{array}{l}(6.6 \pm 0.5) \times 10^{-11} \\
(6.5 \pm 0.7) \times 10^{-11} \\
(6.8 \pm 0.3) \times 10^{-11}\end{array}$ \\
\hline $\begin{array}{l}\text { Pseudocumene } \\
\text { volume }=1 \mathrm{ml} \\
\text { volume }=5 \mathrm{ml} \\
\text { volume }=100 \mathrm{ml}\end{array}$ & $\begin{array}{l}(-3 \pm 13) \times 10^{-10} \\
(7 \pm 27) \times 10^{-10} \\
(9.3 \pm 1.0) \times 10^{-8}\end{array}$ & $\begin{array}{c}<2.2 \times 10^{-11} \\
<1.2 \times 10^{-11} \\
(1.1 \pm 0.1) \times 10^{-11}\end{array}$ & $\begin{aligned}<2.8 \times 10^{-15} \\
\quad<1.5 \times 10^{-15} \\
(1.4 \pm 0.1) \times 10^{-15}\end{aligned}$ \\
\hline $\begin{array}{c}\text { Liquid Scintillator } \\
\text { (commercial) } \\
\text { volume }=1 \mathrm{ml} \\
\text { volume }=5 \mathrm{ml} \\
\text { volume }=50 \mathrm{ml}\end{array}$ & $\begin{array}{l}(9.6 \pm 0.5) \times 10^{-8} \\
(4.4 \pm 0.2) \times 10^{-7} \\
(4.3 \pm 0.4) \times 10^{-6}\end{array}$ & $\begin{array}{c}(1.10 \pm 0.06) \times 10^{-9} \\
(1.01 \pm 0.04) \times 10^{-9} \\
(1.0 \pm 0.1) \times 10^{-9}\end{array}$ & $\begin{array}{c}(1.38 \pm 0.07) \times 10^{-13} \\
(1.27 \pm 0.06) \times 10^{-13} \\
(1.3 \pm 0.1) \times 10^{-13}\end{array}$ \\
\hline
\end{tabular}

Table 3: Summary of the results of the various AMS measurements with different configurations. The two measurements with small volume of pseudocumene did not give statistically significant results so that only $90 \%$ confidence level limits are quoted. 


\subsubsection{Blank (Sample-less) Measurement}

A measurement was performed where the exact procedures of Figure 2 as described in Section 2.1 were followed - except that there were no initial samples. This allows the studies of the intrinsic ${ }^{39} \mathrm{~K}$ background due to the chemical processing procedures.

The AMS measurements gave $(73561 \pm 5565)$ counts of ${ }^{39} \mathrm{~K}$ per $100 \mathrm{~s}$ at a ${ }^{63} \mathrm{Cu}^{-}$ current of $778 \mathrm{nA}$ at the LECup. Using calibration factors derived in Section 3.3.2, this corresponds to a background of

$$
\left[{ }^{39} \mathrm{~K} / \mathrm{Cu}\right]_{\mathrm{Bkg}}=(1.62 \pm 0.12) \times 10^{-8} \mathrm{~g} / \mathrm{g} .
$$

After proper beam current normalizations are performed, this background is subtracted off from the various AMS measurements, from which the intrinsic ${ }^{39} \mathrm{~K}$ contaminations in the samples can be derived.

As discussed in Section 3.1, the beam-related background from the blind target measurement is only of the order of $10{ }^{39} \mathrm{~K}$ counts per second. Accordingly, the measured ${ }^{39} \mathrm{~K}$ background of Eq. 8 is expected to be introduced pre-dominantly in the processing procedures.

\subsubsection{Reference Samples}

A series of potassium-copper standard samples were prepared. The copper was of ultrapure grade, with purity level better than ppm and potassium contaminations less than $10 \mathrm{ppb}$. Added to it were $65 \%$ ultra-pure nitric acid and $99.99 \%$ potassium nitrate $\left(\mathrm{KNO}_{3}\right)$. The ${ }^{39} \mathrm{~K}$ levels were independently verified by Spark Source Mass Spectrometry. The exact processing procedures of Figure 2. were followed.

The sample with highest potassium concentration, at $\left[{ }^{39} \mathrm{~K} / \mathrm{Cu}\right]=1.50 \times 10^{-7} \mathrm{~g} / \mathrm{g}$, was used for calibration purposes. The ${ }^{39} \mathrm{~K}$-counts at the AMS detector, after subtraction of the intrinsic background of Eq. 8, give rise to the ${ }^{39} \mathrm{~K}$ contamination level in the sample. The number of copper atoms in the beam was derived from Eq. 4 using the ${ }^{63} \mathrm{Cu}^{-}$beam current at the LECup $\left(\mathrm{I}_{\mathrm{LE}}\left({ }^{63} \mathrm{Cu}^{-}\right)\right)$as input. The overall calibration factor is:

$$
\left[{ }^{39} \mathrm{~K} / \mathrm{Cu}\right]=1.5 \times 10^{-7} \cdot \frac{\mathrm{R}_{\mathrm{AMS}}\left({ }^{39} \mathrm{~K}\right)}{0.92 \times 10^{6}} \cdot \frac{\mathrm{I}_{\mathrm{LE}}\left({ }^{63} \mathrm{Cu}^{-}\right)}{1000 \mathrm{nA}} \mathrm{g} / \mathrm{g},
$$

where $\mathrm{R}_{\text {AMS }}\left({ }^{39} \mathrm{~K}\right)$ is the ${ }^{39} \mathrm{~K}$-counts measured in the AMS detector in $100 \mathrm{~s}$. This relation was applied in all the other measurements listed in Table 3.

\footnotetext{
"Supplier: Alfa Aesar-A Johnson Matthey Company
} 


\begin{tabular}{|l|c|c|c|}
\hline Samples & $\alpha$ & {$\left[{ }^{39} \mathrm{~K} /\right.$ sample $](\mathrm{g} / \mathrm{g})$} & $\epsilon$ \\
\hline \hline PPO Solid & $100 \%$ & $\mathrm{Y}_{\mathrm{PPO}}=(3.1 \pm 0.4) \times 10^{-8}$ & - \\
Pure PC & $0.0 \%$ & $\mathrm{Y}_{0}=(1.5 \pm 0.2) \times 10^{-11}$ & - \\
PC+PPO & $0.01 \%$ & $\mathrm{Y}_{\alpha}=(1.8 \pm 0.3) \times 10^{-11}$ & $1.0 \pm 1.3$ \\
PC+PPO & $0.1 \%$ & $\mathrm{Y}_{\alpha}=(4.4 \pm 0.8) \times 10^{-11}$ & $1.0 \pm 0.3$ \\
PC+PPO & $1.0 \%$ & $\mathrm{Y}_{\alpha}=(3.2 \pm 0.1) \times 10^{-10}$ & $1.0 \pm 0.1$ \\
\hline
\end{tabular}

Table 4: Results from AMS measurements with varying PPO concentration in PC.

Two additional samples with 10 and 100 times lower potassium concentrations were prepared to cross-check the procedures. The AMS measurement results, shown in Table 3, were derived after applying this conversion factor and subtracting the normalized background. They are in excellent agreement with the expected values.

The ${ }^{39} \mathrm{~K}$-levels in $\left[{ }^{39} \mathrm{~K} /\right.$ sample $]$ units for the subsequent samples can be derived through

$$
\left[{ }^{39} \mathrm{~K} / \text { sample }\right]=\left[{ }^{39} \mathrm{~K} / \mathrm{Cu}\right] \cdot\left[\frac{\mathrm{M}(\mathrm{Cu})}{\mathrm{M}(\text { sample })}\right]
$$

where $\mathrm{M}(\mathrm{Cu})$ and $\mathrm{M}$ (sample) are the controlled and known masses of copper and the sample, respectively. It can be seen that given a sample with definite $\left[{ }^{39} \mathrm{~K} /\right.$ sample], the uncertainties in the measurement of $\left[{ }^{39} \mathrm{~K} / \mathrm{Cu}\right]$ can be reduced by using larger sample mass for the same amount of copper carrier introduced. The final results in $\left[{ }^{40} \mathrm{~K} /\right.$ sample] follow simply from taking ratios on the isotopic abundance between ${ }^{40} \mathrm{~K}$ and ${ }^{39} \mathrm{~K}$.

\subsubsection{PPO Concentration Scan}

The relation established in Eq. 9 is applicable for calibrations of AMS measurements in solid samples following the processing procedures of Figure 2. For organic liquid samples, an extra factor - the survival efficiency of potassium at the solid residuals after vacuum evaporation $(\epsilon)$ - has to be evaluated. This was studied by measuring the ${ }^{39} \mathrm{~K}$-yields in solid PPO ( $\left.\mathrm{Y}_{\mathrm{PPO}}\right)$ and comparing it to those samples with PPO mixed with PC. The efficiency $\epsilon$ is given by

$$
\epsilon=\frac{\mathrm{Y}_{\alpha}-\mathrm{Y}_{0}}{\alpha \cdot \mathrm{Y}_{\mathrm{PPO}}}
$$

where $\mathrm{Y}_{\mathrm{PPO}}, \mathrm{Y}_{0}$ and $\mathrm{Y}_{\alpha}$ are, respectively, the ${ }^{39} \mathrm{~K}$-levels in PPO solid, pure PC liquid without PPO, and PC mixed with PPO in known fractions $\alpha$. The results are summarized in Table 4. The most accurate measurement is one with a high concentration of PPO $(\alpha=1 \%)$, giving $\epsilon=(1.0 \pm 0.1)$. This result demonstrates that most potassium in the $\mathrm{PPO}+\mathrm{PC}$ solution remained in the solid residuals after evaporation. Measurements with 
smaller PPO concentrations were still consistent with complete potassium extraction, but with larger uncertainties due to limited statistics above the background.

\subsubsection{Liquid Scintillator, Solute and Solvent}

Samples of different masses of pure PPO powder, pure PC liquid, as well as their mixtures as liquid scintillators were measured, following the proper procedures of calibrations and background subtraction discussed above. The results are summarized in Table 3. Consistent results were obtained for the two decades variations in sampling mass, in both $\left[{ }^{39} \mathrm{~K} / \mathrm{Cu}\right]$ and $\left[{ }^{40} \mathrm{~K} /\right.$ sample $]$.

The liquid scintillator sample was commercially mixed. The measured ${ }^{40} \mathrm{~K}$ contamination was

$$
\left[{ }^{40} \mathrm{~K} / \mathrm{LS}\right]=(1.3 \pm 0.1) \times 10^{-13} \mathrm{~g} / \mathrm{g}
$$

implying equivalently a ${ }^{40} \mathrm{~K}$-activity of $\sim 3 \mathrm{~kg}^{-1}$ day $^{-1}$. Such commercial LS sample is not yet good enough for the low background experiments. Further purifications are therefore necessary. The source of contaminations come primarily from the PPO solute, such that it would be more effective to focus the purification program on it. The best measurement is, expectedly, one on pure PC at the largest sampling mass, where

$$
\left[{ }^{40} \mathrm{~K} / \mathrm{PC}\right]=(1.4 \pm 0.1) \times 10^{-15} \mathrm{~g} / \mathrm{g}
$$

The expected ${ }^{40} \mathrm{~K}$-decay rate is $(0.024 \pm 0.003) \mathrm{kg}^{-1}$ day ${ }^{-1}$. These characteristic features should be valid in general - that the contaminations in organic liquid scintillator come primarily from the dye solutes while the liquid solvent are orders of magnitude cleaner. Another two measurements of PC with much smaller sampling masses did not give rise to statistically significant excess of the $\left[{ }^{39} \mathrm{~K} / \mathrm{Cu}\right]$ ratio, such that only $90 \%$ confidence level upper limits are derived [1] in Table 3. The limits are consistent with the measured results of Eq. 13.

It is instructive to compare the results of Tables $3 \& 4$, which are from the measurements on two different batches of PPO and PC samples from the same supplier. The ${ }^{39} \mathrm{~K}$ contaminations of the two batches of PPO are, respectively, $\mathrm{Y}_{\mathrm{PPO}}=(5.4 \pm 0.2) \times 10^{-7} \mathrm{~g} / \mathrm{g}$ and $(3.1 \pm 0.4) \times 10^{-8} \mathrm{~g} / \mathrm{g}$, while the those for the $\mathrm{PC}$ are $\mathrm{Y}_{0}=(1.1 \pm 0.1) \times 10^{-11} \mathrm{~g} / \mathrm{g}$ and $(1.5 \pm 0.2) \times 10^{-11} \mathrm{~g} / \mathrm{g}$. The differences indicate the range of variations of potassium levels in different production batches among the same materials. 


\subsection{Limiting Sensitivities}

An important parameter to characterize the performance of this measurement technique is the limiting sensitivity. It represents the upper limits that can be set for samples where no excess of ${ }^{39} \mathrm{~K}$-counts above background are observed - or alternatively, the minimal contamination levels that will produce a positive measurement.

The measurements of the CsI samples do not involve chemical pre-processing. Therefore, the sensitivity is limited by the ion-beam related background measured in the "blind target" run discussed in Section 3.1. The ${ }^{39} \mathrm{~K}$ background count rates of $<50$ per second at the AMS detector can be translated to limiting sensitivities following the same normalization steps of Section 3.2:

$$
\begin{aligned}
& {\left[{ }^{39} \mathrm{~K} / \mathrm{CsI}\right]_{\text {limit }} \sim 6 \times 10^{-9} \mathrm{~g} / \mathrm{g}, \quad \text { or equivalently }} \\
& {\left[{ }^{40} \mathrm{~K} / \mathrm{CsI}\right]_{\text {limit }} \sim 8 \times 10^{-13} \mathrm{~g} / \mathrm{g} .}
\end{aligned}
$$

For organic liquid, potassium introduced during the pre-processing procedures is the dominant background. The limiting sensitivities of $\left[{ }^{39} \mathrm{~K} / \mathrm{Cu}\right]$ can be derived from the uncertainties of the background blank measurement in Eq. 8, giving

$$
\left[{ }^{39} \mathrm{~K} / \mathrm{Cu}\right]_{\text {limit }} \sim 2 \times 10^{-9} \mathrm{~g} / \mathrm{g} .
$$

To convert into $\left[{ }^{39} \mathrm{~K} /(\right.$ Org.Liq. $\left.)\right]$ units, the relation of Eq. 9 is used. The ratio of $[\mathrm{M}($ sample $) / \mathrm{M}(\mathrm{Cu})]$ is taken from the measurement with the largest liquid sample volume $(100 \mathrm{ml})$ where the extraction of the contaminants was successfully demonstrated. The sensitivities are

$$
\begin{aligned}
& {\left[{ }^{39} \mathrm{~K} /(\text { Org.Liq. })\right]_{\text {limit }} \sim 2 \times 10^{-13} \mathrm{~g} / \mathrm{g}, \text { or equivalently }} \\
& \left.\left[{ }^{40} \mathrm{~K} / \text { (Org.Liq. }\right)\right]_{\text {limit }} \sim 3 \times 10^{-17} \mathrm{~g} / \mathrm{g} .
\end{aligned}
$$

The improvement of sensitivities in Eqs. 16\&14 of organic liquid over solid CsI powder follows from the $[\mathrm{M}(\mathrm{Cu}) / \mathrm{M}($ sample $)]$ ratio in Eq. 10. At a typical $\mathrm{M}(\mathrm{Cu}) \sim 10 \mathrm{mg}$ and the largest liquid extraction volume of $100 \mathrm{ml}$ [that is, M(sample) 100 g], an enhancement factor of $10^{-4}$ is readily attained in the evaporation and extraction processes.

\section{Summary and Outlook}

In this article, we report the first measurement of ultra-low potassium contaminations in an inorganic salt (CsI) and in an organic scintillator liquid (LS=PC+PPO) using accelerator mass spectrometry. Comparable sensitivities to the neutron activation techniques 
were achieved. Potassium were positively identified in samples of commercially available CsI and LS, at the contamination levels of $7 \times 10^{-11} \mathrm{~g} / \mathrm{g}$ and $1.3 \times 10^{-13} \mathrm{~g} / \mathrm{g}$, respectively. The radioactivity in the LS is mainly due to the dye solutes. The limiting sensitivities of the techniques are of the order of $10^{-13} \mathrm{~g} / \mathrm{g}$ of ${ }^{40} \mathrm{~K}$ in solid powder and of $10^{-17} \mathrm{~g} / \mathrm{g}$ of ${ }^{40} \mathrm{~K}$ in an organic liquid.

In the case of organic liquid, the sensitivities are limited by ambient potassium impurities introduced during the chemical processing of the liquid depicted in Figure 2. Further improvement can be made along these directions. The beam-related background is small in comparison. A boost in sensitivities can also be made with the use of larger initial liquid volume for evaporation. The largest sample demonstrated in the present studies is $100 \mathrm{ml}$. Extensions to treatment of liter-scale sample are expected to be technically similar, such that a limiting sensitivity of $\sim 10^{-18} \mathrm{~g} / \mathrm{g}$ on liquid scintillator using AMS should be possible.

This work demonstrate the feasibilities of measuring ultra-low impurities of naturallyoccurring yet unstable isotopes with AMS. Accordingly, other radio-isotopes which are

problematic to low-background experiments, such as the ${ }^{238} \mathrm{U}$ and ${ }^{238} \mathrm{Th}$ series as well as ${ }^{87} \mathrm{Rb},{ }^{113} \mathrm{Cd},{ }^{115} \mathrm{In},{ }^{138} \mathrm{La}$ and ${ }^{176} \mathrm{Lu}$, can also be measured by the AMS techniques. The goals of our future efforts would be to devise schemes to measure some of these isotopes. Extensions to Rb will be relatively straight-forward, while the measurements of the ${ }^{238} \mathrm{U}$ and ${ }^{238} \mathrm{Th}$ series will involve upgrades of the present accelerator systems.

\section{Acknowledgments}

The authors are grateful to M. Lin, S.H. Li, Y.D. Chen, A.L. Li, J. Li, K.X. Liu, B.F. Ni, H.Q. Tang, W.Z. Tian and Z.Y. Zhou for helpful discussions, as well as to Q.B. You, Y.B. Bao, Y.M. Hu and the technical staff at CIAE for smooth accelerator operation. This work is supported by contract 10375099 from the National Natural Science Foundation, China.

\section{References}

[1] See the respective sections in Review of Particle Physics, J. Phys. G 33, 1 (2006), for details and references.

[2] H.T. Wong, Mod. Phys. Lett. A 19, 1207 (2004). 
[3] "Accelerator Mass Spectrometry", C. Tuniz et al., CRC Press (1998).

[4] D. Elmore and F.M. Phillips, Science 346, 543 (1987).

[5] C. Tuniz, Rad. Phys. \& Chem. 61, 317 (2001).

[6] K.J. Dong et al., nucl-ex/0512003, Nucl. Instrum. Methods B, in press (2006).

[7] D. Elmore et al., Nature 286, 138 (1980).

[8] G. Heusser, Nucl. Instrum. Methods B 58, 79 (1991);

P. Jagam and J.J. Simpson, Nucl. Instrum. Methods A 324, 389 (1993).

[9] G. Alimonti et al., Nucl. Instrum. Methods A 406, 411 (1998).

[10] R.V. Hentig et al., Fres. J. Anal. Chem. 360, 664 (1998).

[11] Z. Djurcic et al., Nucl. Instrum. Methods A 507, 680 (2003).

[12] U. Fehn et al., Nature 323, 707 (1986);

J.C. Rucklidge, G.C. Wilson and L.R. Kilius, Nucl. Instrum. and Methods B 52, 507 (1990);

H.E. Gove et al., Nucl. Instrum. and Methods B 52, 502 (1990).

[13] H.B. Li et al., Nucl. Instrum. Methods A 459, 93 (2001);

Y. Liu et al., Nucl. Instrum. Methods A 482, 125 (2002).

[14] H. Park et al., Nucl. Instrum. Methods A 491, 460 (2002);

T.Y. Kim et al., Nucl. Instrum. Methods A 500, 337 (2003).

[15] F.D. McDaniel et al., Nucl. Instrum. and Methods B 190, 826 (2002);

L.J. Mitchell et al., Nucl. Instrum. and Methods B 219, 455 (2004).

[16] S. Jiang et al., Nucl. Instrum. Methods B 52, 285 (1990);

S. Jiang et al., Nucl. Instrum. Methods B 92, 61 (1994).

[17] Y.F. Zhu et al., Nucl. Instrum. Methods A 557, 490 (2006). 


\section{HI-13 TANDEM ACCELERATOR}

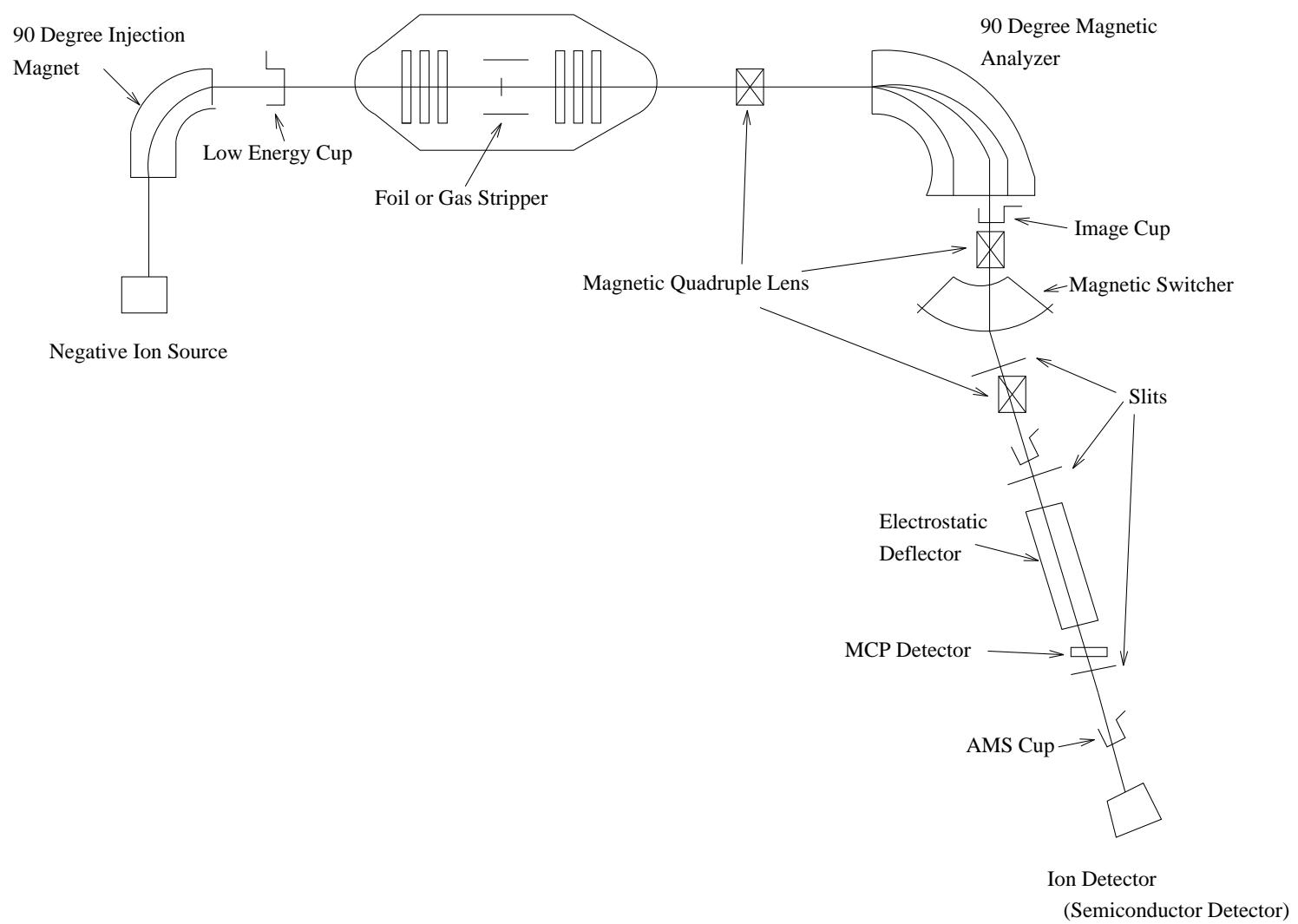

Figure 1: Schematic layout of the 13 MV Tandem Accelerator Facility at CIAE when it is optimized for AMS applications. 


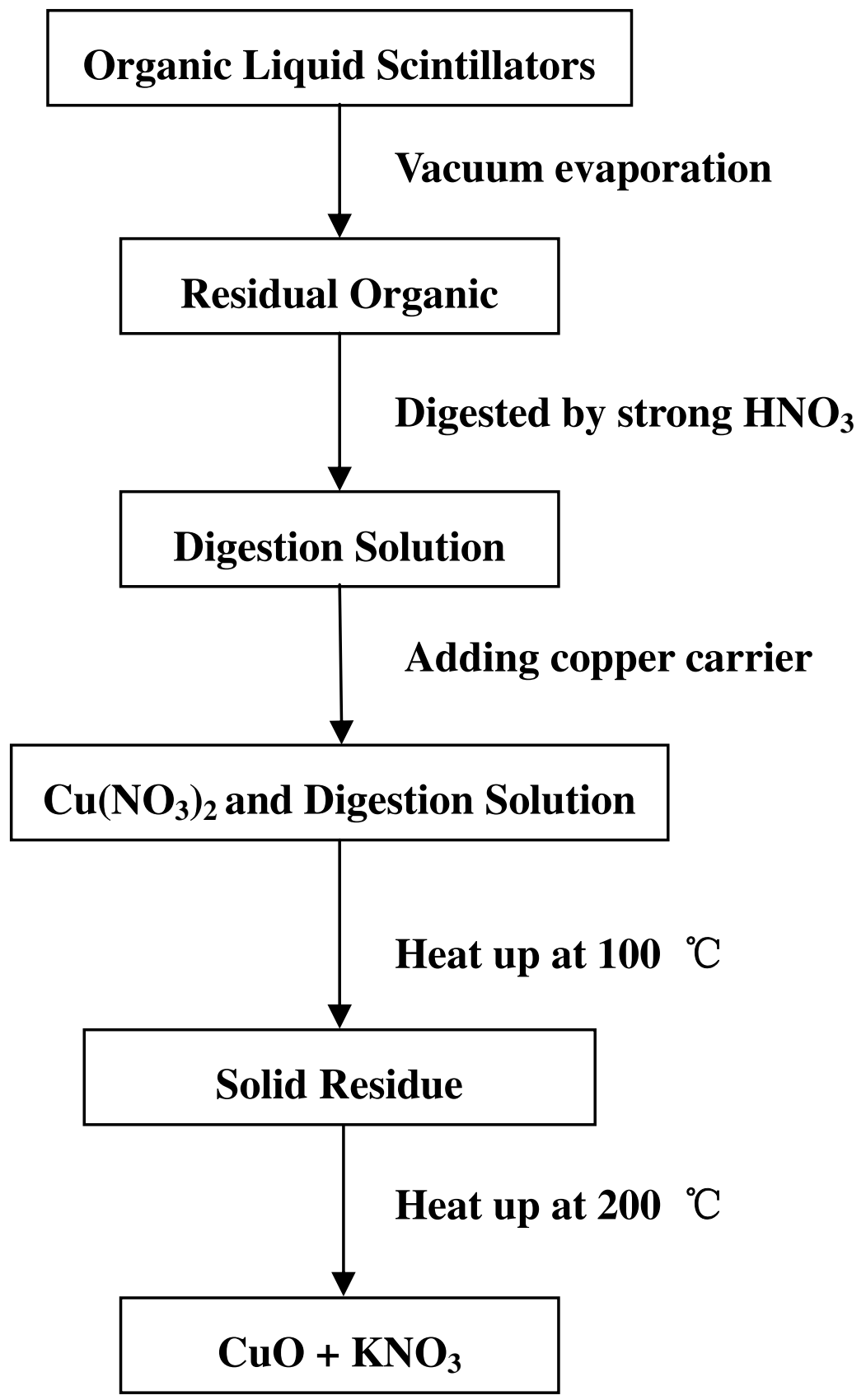

Figure 2: The flow chart of samples preparation for organic liquid scintillator. 


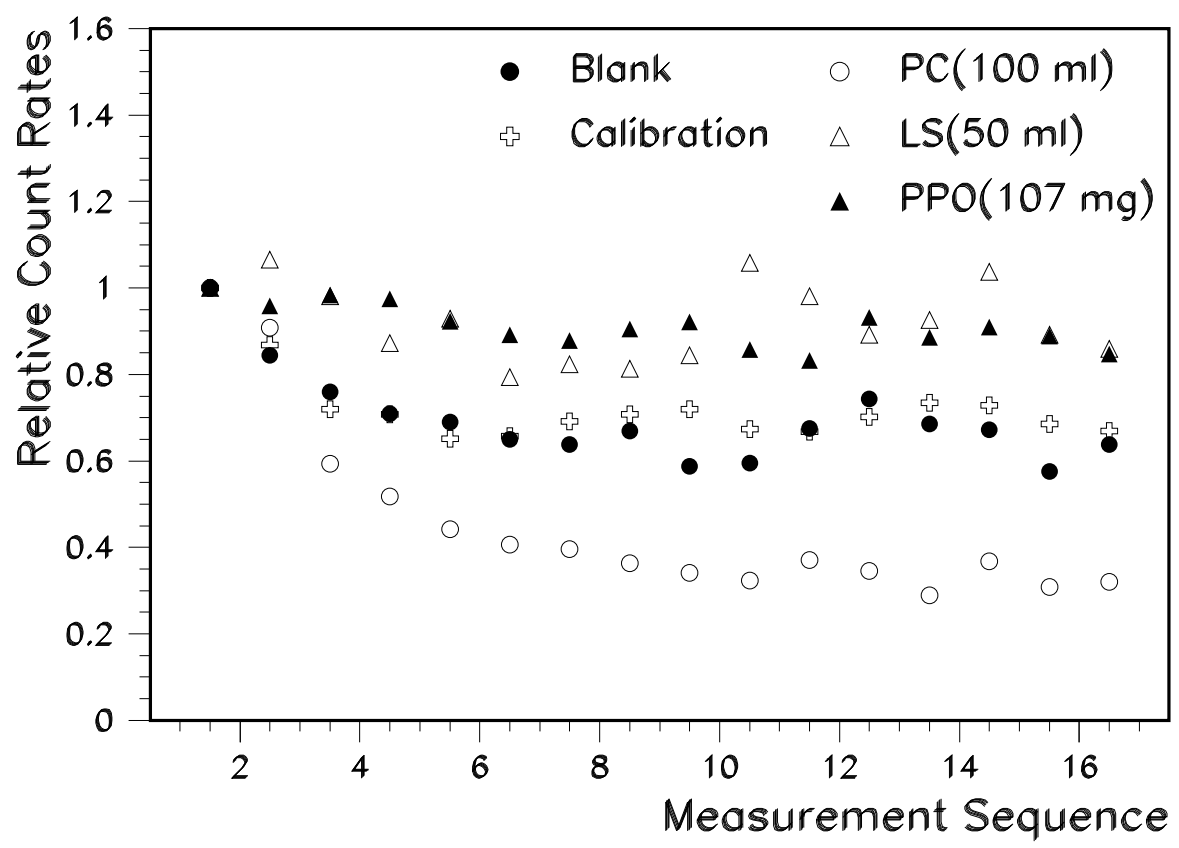

Figure 3: Time evolution of the ${ }^{39} \mathrm{~K}$-counts for some selected samples. Results after the sixth measurements since the start of data taking were adopted for subsequent analysis.

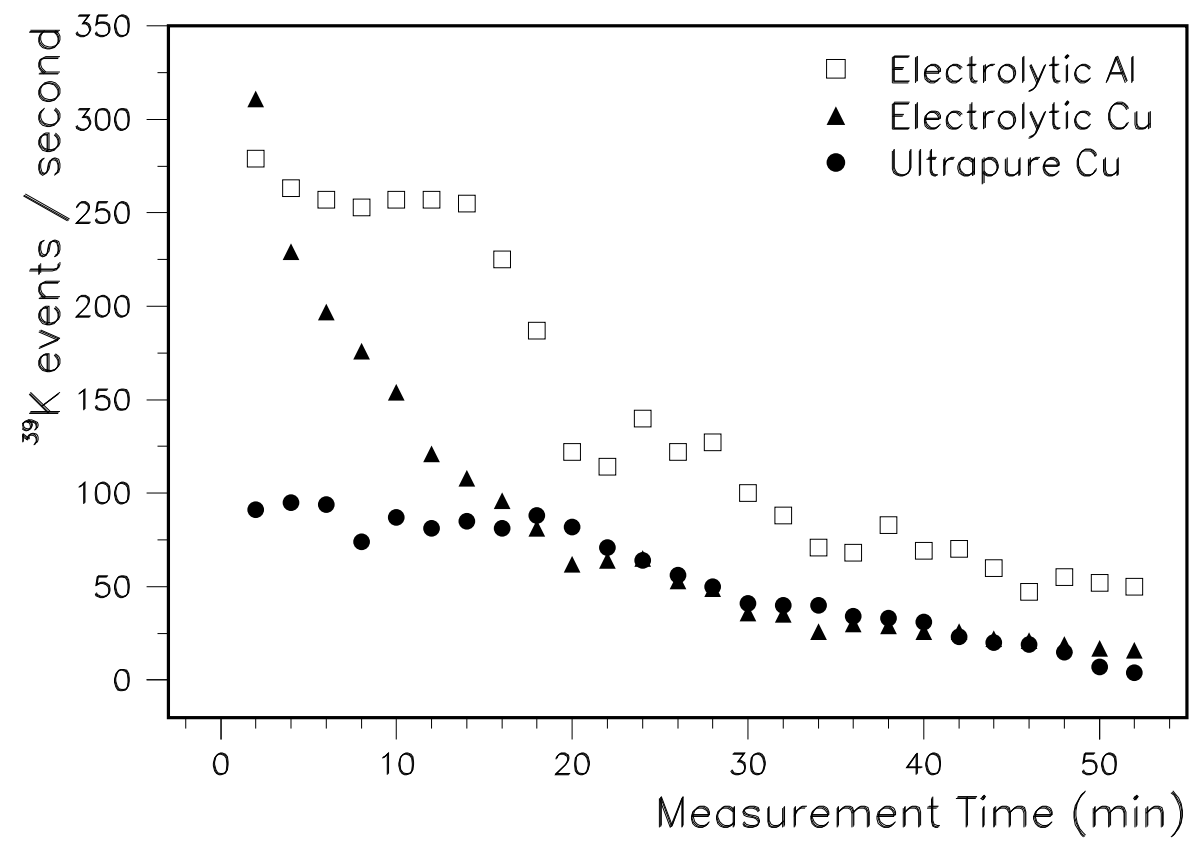

Figure 4: Time evolution of the ${ }^{39} \mathrm{~K}$-counts for the blind target runs. 